\title{
Surface and Interface Chemistry in Colloidal Quantum Dots for Solar Applications studied by X-ray Photoelectron Spectroscopy \\ DOI:
}

10.1002/tcr.201800085

\section{Document Version}

Accepted author manuscript

Link to publication record in Manchester Research Explorer

Citation for published version (APA):

Clark, P. C. J., \& Flavell, W. (2018). Surface and Interface Chemistry in Colloidal Quantum Dots for Solar Applications studied by X-ray Photoelectron Spectroscopy. Chemical Record. https://doi.org/10.1002/tcr.201800085

Published in:

Chemical Record

\section{Citing this paper}

Please note that where the full-text provided on Manchester Research Explorer is the Author Accepted Manuscript or Proof version this may differ from the final Published version. If citing, it is advised that you check and use the publisher's definitive version.

\section{General rights}

Copyright and moral rights for the publications made accessible in the Research Explorer are retained by the authors and/or other copyright owners and it is a condition of accessing publications that users recognise and abide by the legal requirements associated with these rights.

\section{Takedown policy}

If you believe that this document breaches copyright please refer to the University of Manchester's Takedown Procedures [http://man.ac.uk/04Y6Bo] or contact uml.scholarlycommunications@manchester.ac.uk providing relevant details, so we can investigate your claim.

\section{OPEN ACCESS}


Surface and Interface

Dedicated to all the PhD students in the Photon Science Institute, Chemistry in Colloidal Quantum Dots for Solar Applications studied by X-ray Photoelectron Spectroscopy

Pip C. J. Clark ${ }^{[a, b]}$ and Wendy R. Flavel|*[a] office 2.323

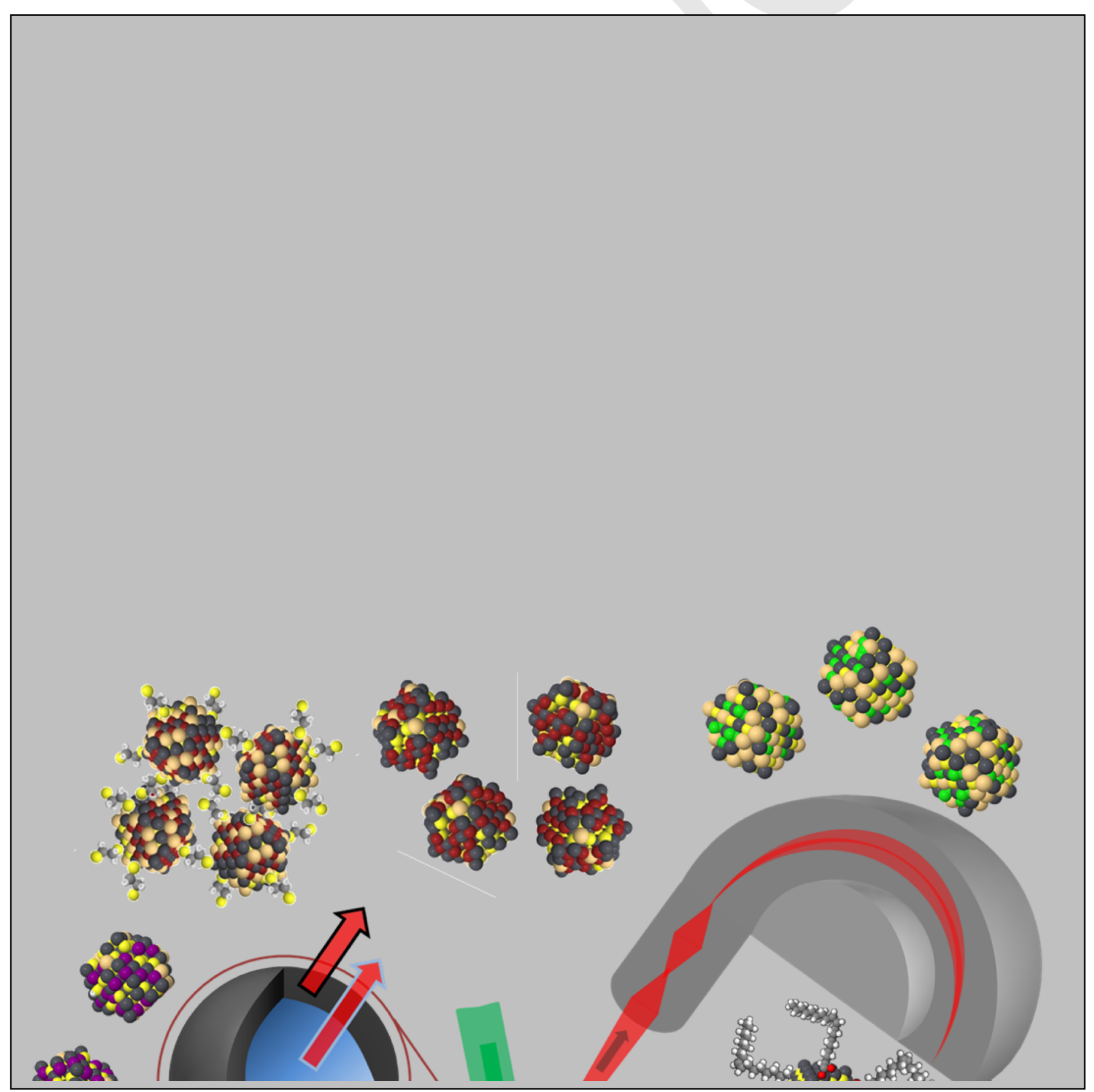


Abstract: Control of the surface and interface chemistry of colloidal quantum dots (CQDs) is critical to achieving a product with good air stability and high performing optoelectronic devices. Through various surface passivation treatments, vast improvements have been made in fields such as CQD photovoltaics, however devices have not currently reached commercial standards. We show how a better understanding of exactly how surface treatments act on CQD surfaces, and the effect surface composition bestows on air stability and device performance can be achieved with X-ray photoelectron spectroscopy (XPS). We illustrate this with PbS-based CQDs, using XPS to measure oxidation processes, and to quantify the composition of the topmost surface layer after different surface treatments. We also demonstrate the use of synchrotron radiation-excited depth-profiling XPS, a powerful technique for determining the surface composition, chemistry and structure of CQDs. This review describes our recent progress in characterization of CQD surfaces using SR-excited depth profiling XPS and other photoemission techniques.

\section{Introduction}

Semiconducting colloidal quantum dots (CQDs) offer exciting optical properties such as a tunable band gap, and efficient multiple exciton generation. ${ }^{1}$ However CQDs have imperfect surfaces due to their growth, and undercoordinated atoms on the surface with dangling bonds produce trap states. ${ }^{2}$ The development of colloidal quantum dot surface treatments to efficiently passivate trap states has been integral to the improvements in CQD-based optoelectronic device performances in recent years. The record power conversion efficiency (PCE) of CQD-based solar cells is now $13.4 \%{ }^{3}$

Due to their small size, CQDs have a high surface:volume ratio, for example in a $3 \mathrm{~nm} C Q D$ (the required size for PbS CQDs to give the optimal band gap for a single junction solar cell) ${ }^{4,5}$ approximately $50 \%$ of the atoms are located at the surface. As a result, many of their properties are surface chemistry dependent This makes characterizing CQD surfaces critical to our understanding of the properties of CQDs and CQD-based devices, and key to further optimization.

The presence of trap states at a CQD surface can cause undesirable effects such as increased non-radiative recombination, and prevents successful transport of charge

\footnotetext{
[a] School of Physics and Astronomy and the Photon Science Institute The University of Manchester

Manchester, M13 9PL

E-mail: wendy.flavell@manchester.ac.uk

[b] Current Address: Institute for Solar Fuels, Helmholtz-Zentrum Berlin für Materialien und Energie $\mathrm{GmbH}$, Hahn-Meitner Platz 1, D-14109 Berlin, Germany
}

carriers out of a CQD. ${ }^{6-8}$ CQDs without a well-passivated surface are also prone to oxidation, which can create more trap states, and reduce the device efficiency and performance lifetime. ${ }^{9,10}$
Many passivation strategies have been developed for CQDs. Long-chain organic ligands are used in synthesis to control the growth size and passivate some of the surface traps, creating a large potential barrier around the CQDs. ${ }^{11}$ However long ligands hinder charge transport out of CQDs as carriers have to tunnel through the large insulating barrier around the CQDs. ${ }^{12}$ This is undesirable in a solar cell which relies on charge carriers moving out of the CQDs, so ligand exchange is required. Ligand exchange is used after synthesis to replace the long organic ligands with shorter ones. These can be organic, such as 3mercaptopropionic (3-MPA), ${ }^{13}$ 1,2-ethanedithiol (EDT), ${ }^{14}$ or butylamine. ${ }^{15}$ These short organic ligands can have tailored functionalized end groups to bind between CQDs reducing the interdot distance, ${ }^{16}$ or between CQDs and an oxide photoanode. ${ }^{17}$ Even when short chain organic ligands are used, their shape and size does not allow them to bind to all the dangling bonds on the CQD surface. For complete coverage, atomic ligands such as halide ions are needed. ${ }^{18}$ Significant improvements in PCE arose from the advent of a hybrid passivation technique which employs both short chain organic and inorganic atomic ligand exchanges. Using this technique, the record power conversion efficiency of CQD solar cells jumped from $4.4 \%$ to $7.4 \%$ in $2011-12 .^{19,20}$ World-wide efforts have since resulted in further improvements from strategies incorporating different halide ions such as bromide and iodide, ${ }^{21-}$ 25 metal salt ligands, ${ }^{26-28}$ and passivation by using thin perovskite structures on the surface. ${ }^{29,30}$ Other surface treatments such as cation exchange (for example exchanging $\mathrm{Pb}$ for $\mathrm{Cd}$ in $\mathrm{PbS}$ CQDs) has led to improvements in deep trap passivation. ${ }^{31}$ In CQD films, the surface chemistry also controls the semiconductor doping levels, which is important for device design. ${ }^{25,32-36}$

Given the range of possible ligand exchange and surface passivation strategies and combinations, characterizing the surface with techniques such as X-ray photoelectron spectroscopy (XPS) and other surface sensitive techniques is incredibly important for fully comprehending the effect of each passivation strategy on the CQD surface. Here we show examples of the ways XPS can be used to study CQD and nanocrystalline films; preparation methods are summarized in Table 1 below.

Table 1. Summary of the preparation methods and treatments applied to the samples studied.

\begin{tabular}{|c|c|c|c|c|c|}
\hline \multirow{2}{*}{$\begin{array}{l}\text { Sectio } \\
n\end{array}$} & \multirow{2}{*}{$\begin{array}{l}\text { Materi } \\
\text { al }\end{array}$} & \multirow{2}{*}{$\begin{array}{l}\text { Synthesi } \\
\text { S } \\
\text { Method }\end{array}$} & \multicolumn{2}{|c|}{ Post synthesis treatment } & \multirow{2}{*}{$\begin{array}{l}\text { Form studied } \\
\text { with XPS }\end{array}$} \\
\hline & & & Liquid-state & $\begin{array}{l}\text { Solid- } \\
\text { state }\end{array}$ & \\
\hline 3.1 & $\begin{array}{l}\mathrm{PbS} \\
\mathrm{NC}\end{array}$ & $\begin{array}{l}\text { Liquid- } \\
\text { liquid }\end{array}$ & - & - & $\begin{array}{l}\text { Nanocrystallin } \\
\text { e thin film }\end{array}$ \\
\hline 3.2 & $\begin{array}{l}\mathrm{PbS} \\
\text { CQDs }\end{array}$ & $\begin{array}{l}\text { Hot } \\
\text { injection }\end{array}$ & $\begin{array}{l}\mathrm{Cd} \text { cation } \\
\text { exchange, } \\
\text { MPA/butylamin } \\
\text { e liqand }\end{array}$ & - & $\begin{array}{l}\text { Drop-casted } \\
\text { onto ITO }\end{array}$ \\
\hline
\end{tabular}


exchange

$\begin{array}{lllll}3.3 & \text { PbS } & \text { Hot } & \text { Cd cation } & \text { Br, EDT, } \\ \text { CQDs } & \text { injection } & \text { exchange solid } \\ & & & \\ & & & \text { ligand } \\ & & \\ & & \\ & & \text { exchang } \\ & & \end{array}$

\section{Photoemission experiments on CQDs and data analysis}

Synchrotron-radiation (SR)-excited depth-profiling XPS is one of very few techniques that can unveil information about the CQD surface structure and composition at the atomic scale. XPS is a surface sensitive, chemically specific and quantitative technique. For SR-excited depth-profiling XPS the ratio of two core level peaks from two different elements are measured and plotted against depth. The elemental ratio of between a species present on the surface and a species present in the core decreases with depth.

The experiment uses the tunability of synchrotron radiation to adjust the sampling depth. The inelastic mean free path (IMFP) for photoelectrons is proportional to the square root of their kinetic energy $(\mathrm{KE}){ }^{37}$ The kinetic energy of photoelectrons is determined by both the binding energy $(\mathrm{BE})$ of the core level they originate from, and the photon energy used for photoemission, by
Pip C. J. Clark received a MPhys (Hons) (Physics) from the University of Manchester in 2014 , and is nearing completion of a PhD under the supervision of Prof. Wendy Flavell. Her research has focused on the surface characterisation and study of materials for future photovoltaic cells, with emphasis on using various synchrotron radiation-excited photoemission techniques. particularly those of interest in the manufacture of 'next-generation' solar cells.

$$
K E=h v-B E+\phi_{A}
$$

where $\phi_{A}$ is the work function of the electron analyzer. Hence the depth probed (proportional to the IMFP and KE) can be controlled by changing the photon energy. For depths of the order of the CQD size, this is possible using soft X-ray synchrotron beamlines having a typical photon energy range of 50-1600 eV. The change in photoelectron intensity with depth for 3 photon energies is plotted schematically against a $3 \mathrm{~nm}$ CQD in Figure 1. An example of depth-profiling XPS ratios of $\mathrm{Cd} / \mathrm{Pb}$ for $\mathrm{Cd}$ found to be on the surface of PbS CQDs is shown in Figure 2A. A clear decrease in the $\mathrm{Cd} / \mathrm{Pb}$ ratio is measured as a function of sampling depth for several $\mathrm{Cd}$ shell thicknesses. X-ray spot sizes are of the order of $100 \times 10 \mu \mathrm{m}^{2}$, so the experiment probes the average response of millions of CQDs.

Shell thicknesses of randomly ordered spherical nanoparticles can be calculated with various analytical methods, including those developed by Shard et al. ${ }^{38,39}$ These have been implemented in two ways. The first method predicts the variation in the ratio of shell and core elements with varying sampling depth for a fixed core size and variable shell thickness. Comparison with the data (for example the data presented in Figure 2A) gives information on the shell thickness and whether alloying between the core and shell is present. In the second method the core diameter, shell elements to core elements ratio, and other material parameters are used to calculate the shell thickness for each sampling depth. ${ }^{40,41}$

Preparation of the CQD samples for photoemission measurements is important. The CQDs can either be drop casted from solution onto a conductive substrate (forming a thin layer of CQDs) or deposited as a film (many layers) by other techniques. For the drop-casting method, the substrate must not contain an element present in the CQDs and ligands to avoid complications in analysis. We have commonly used indiumdoped tin oxide, fluorine-doped tin oxide and silicon, and goldcoated silicon. As photoemission measurements are taken in ultra-high vacuum, the solvent must have a low boiling point so that it quickly evaporates and allow low pressures to be reached. The ligands are also important to consider. Shorter ligands help to prevent charging in photoemission experiments, which is crucial to our work involving high flux synchrotron radiation. Charging of samples during photoemission can prevent proper identification of chemical environments or prohibit measurement of the sample at all in extreme cases. We found ligands such as butylamine and 3-MPA are short enough to prevent charging in drop-casted CQDs. ${ }^{17,40-43}$ Shorter ligands also increase the signal from the CQDs compared to longer ligands, since photoelectrons from the CQD must travel through a ligand layer without scattering to contribute to a core level peak. The CQDs in solution must also be washed to remove the residual synthesis and excess ligands and other organic matter, in order to prevent charging and reduction of the CQD signal. Figure $2 \mathrm{~B}$ shows the ratios of bound ligands to the CQD signal, for a range of $\mathrm{PbS} / \mathrm{CdS} \mathrm{CQDs}$. It is clear that two of the samples show a much higher ligand signal than the others, due to less successful 
washing. Figure $2 \mathrm{C}$ shows a schematic picture of one of the $\mathrm{PbS} / \mathrm{CdS} \mathrm{CQDs}$ with synthesis ligand (pre-ligand-exchange) and unbound ligands still present after non-optimal washing as determined by XPS.

The alternative sample preparation, CQD films, allows the use of solid-state ligand exchanges during the spin-coating or dipcoating process used to fabricate the film. This is useful for the study of solid-state ligand exchange effects on CQD surfaces which are commonly used in CQD-based device manufacturing. ${ }^{44,45}$ CQD films have a higher density of CQDs by area than is typically achieved with the drop-casting method, and therefore a greater XPS signal is achieved, which is beneficial to the experiment. However in some situations it may not be possible to deposit the CQDs into a film, for example if a solid-state ligand exchange changes the surface chemistry of interest, and so the drop casting technique must be used in these cases.

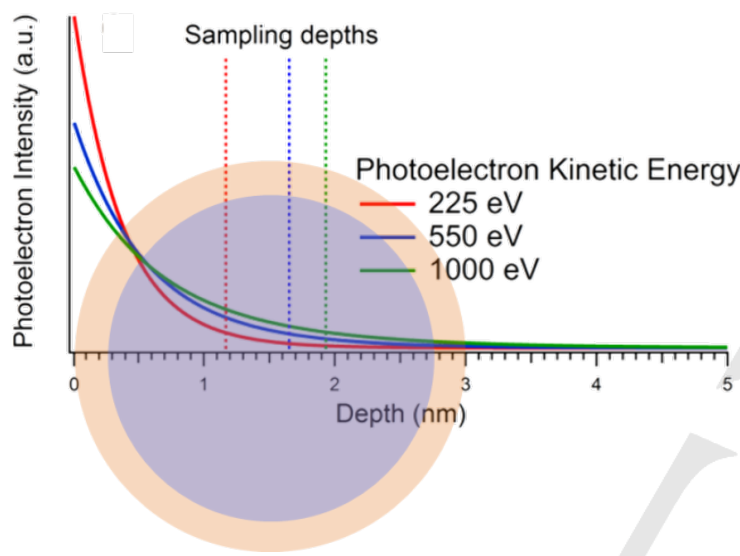

Figure 1. Schematic diagram of a core-shell CQD showing the distribution of the XPS signal at three photoelectron kinetic energies.

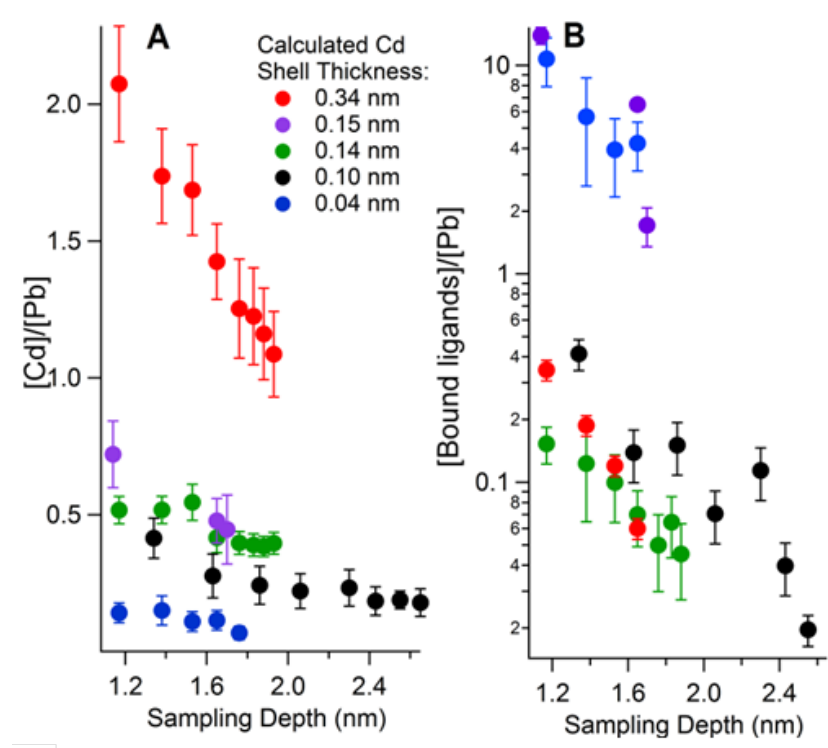

C

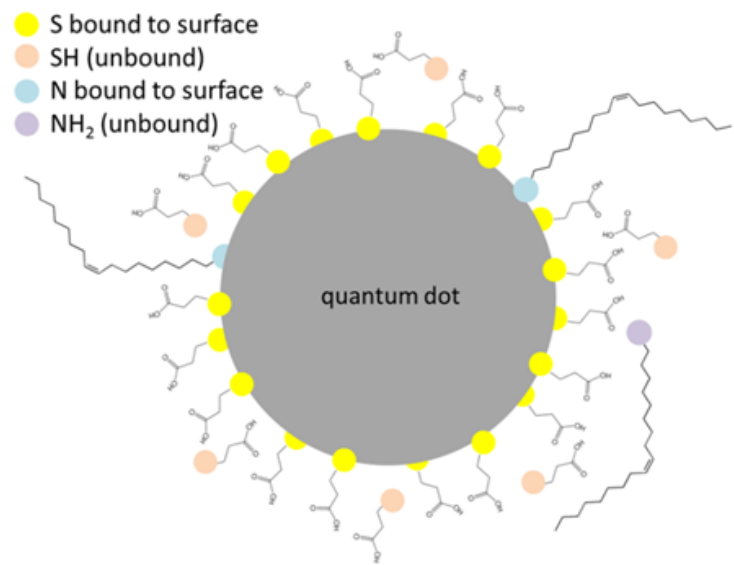

Figure 2. Elemental ratios as a function of calculated sampling depth for (A) $\mathrm{Cd}$ to $\mathrm{Pb}$, and $(\mathrm{B})$ ligands to $\mathrm{Pb}$ as calculated from synchrotron- excited $\mathrm{X}$-ray Photoelectron Spectroscopy. Each sample is labelled with its effective CdS shell thickness, calculated from these ratios. (C) Schematic drawing showing the ligands attached to the $0.15 \mathrm{~nm}$ CdS shell PbS sample, with ligands present in the relative amounts determined by XPS. ${ }^{4}$

\section{Studies of Oxidation and Passivation}

By using SR-excited depth-profiling XPS together with valence band photoemission and the chemical specificity of XPS, our experiments contribute to the understanding of surface oxidation and its effect on the electronic structure of CQDs and CQDbased device behavoir. This account summarizes our recent work in isolating the signal from the topmost CQD layer using depth-profiling XPS, leading to improved understanding of their surface chemistry and its effects.

\subsection{Surface Oxidation Mechanism}


Poorly passivated CQDs are highly reactive and prone to surface oxidation; in addition to surface trap formation, very rapid oxidation of the outer surfaces of colloidal NCs of $\mathrm{PbS}^{6}$ and $\mathrm{PbSe}^{46}$ has been demonstrated. In the case of unpassivated $\mathrm{PbS}$, up to two-thirds of the volume of the NC may be oxidized after a few hours' exposure to air. ${ }^{10}$ Such oxidation is particularly undesirable as it reduces the diameter of the core of the NC, blue-shifting its optical absorption. ${ }^{10,46}$ In this scenario, SRexcited depth-profiling XPS is a powerful tool in allowing us to identify the oxidation products and their depth distribution in the CQDs. In optimum cases, it may also allow us to comment on the oxidation mechanism. A case in point is the oxidation of $\mathrm{PbS}$, a reaction long-studied because of its importance in mineral beneficiation using froth flotation, and in the extraction of lead from ore using hydrometallurgical operations such as leaching. ${ }^{47-49}$ The question of whether or not the reaction proceeds congruently (with dissolution of $\mathrm{Pb}$ and $\mathrm{S}$ in equivalent amounts) has been extensively debated. ${ }^{50-52}$ We have been able to resolve this in studies of nanocrystalline thin films of $\mathrm{PbS}$ obtained in a straightforward reaction by precipitation at the interface between toluene (containing a $\mathrm{Pb}$ precursor, such as lead diethyldithiocarbamate $\left(\mathrm{Pb}\left(\mathrm{S}_{2} \mathrm{CNEt}_{2}\right)_{2}\right)$ and water (containing $\mathrm{Na}_{2} \mathrm{~S}$ ). ${ }^{53}$ This preparation produces high quality material that is largely free of the organic material that attenuates XPS signals from the inorganic nanocrystals. This yields excellent signal-to-noise levels in the resulting data, allowing a detailed examination of the depth- and timedependence of the surface oxidation. Similar experiments using colloidal QDs are more challenging, because of the presence of large amounts of organic ligand. However, the basic features of the $\mathrm{PbS}$ oxidation reaction determined by Cant et al. ${ }^{53}$

are confirmed in our studies on PbS CQDs. ${ }^{10,40,54,55}$ Figure 3 shows some of the results from a depth- and time-dependent study of the chemical composition of PbS nanocrystals (NCs) as a function of surface ageing in air for periods of up to 9 months. ${ }^{53}$ The peak assignment is shown in Table 2. After ageing in air for one week, it is clear that a significant oxidized lead $(\mathrm{Pb} 2)$ component is present in the $\mathrm{Pb} 4 \mathrm{f}$ signal. This component does not show any strong variation in intensity with sampling depth. The corresponding $S 2 p$ spectra show vanishingly small features due to sulfate (S5) and sulfite (S4), but there is a component due to -SO/-SH/S-C (S2), which is largest at the lowest sampling depth used $(3.3 \mathrm{~nm})$. The picture at this early stage of ageing is of a significant amount of oxidised $\mathrm{Pb}$ (possibly lead oxide, hydroxide, hydroxycarbonate or hydrated oxide), which is not localized only at the topmost sample surface, together with a small amount of -SO/-SH/S-C species that lie predominantly at the surface. This shows clearly that the oxidation reaction is incongruent, with substantial lead oxidation occurring before significant oxidation of sulfur. 

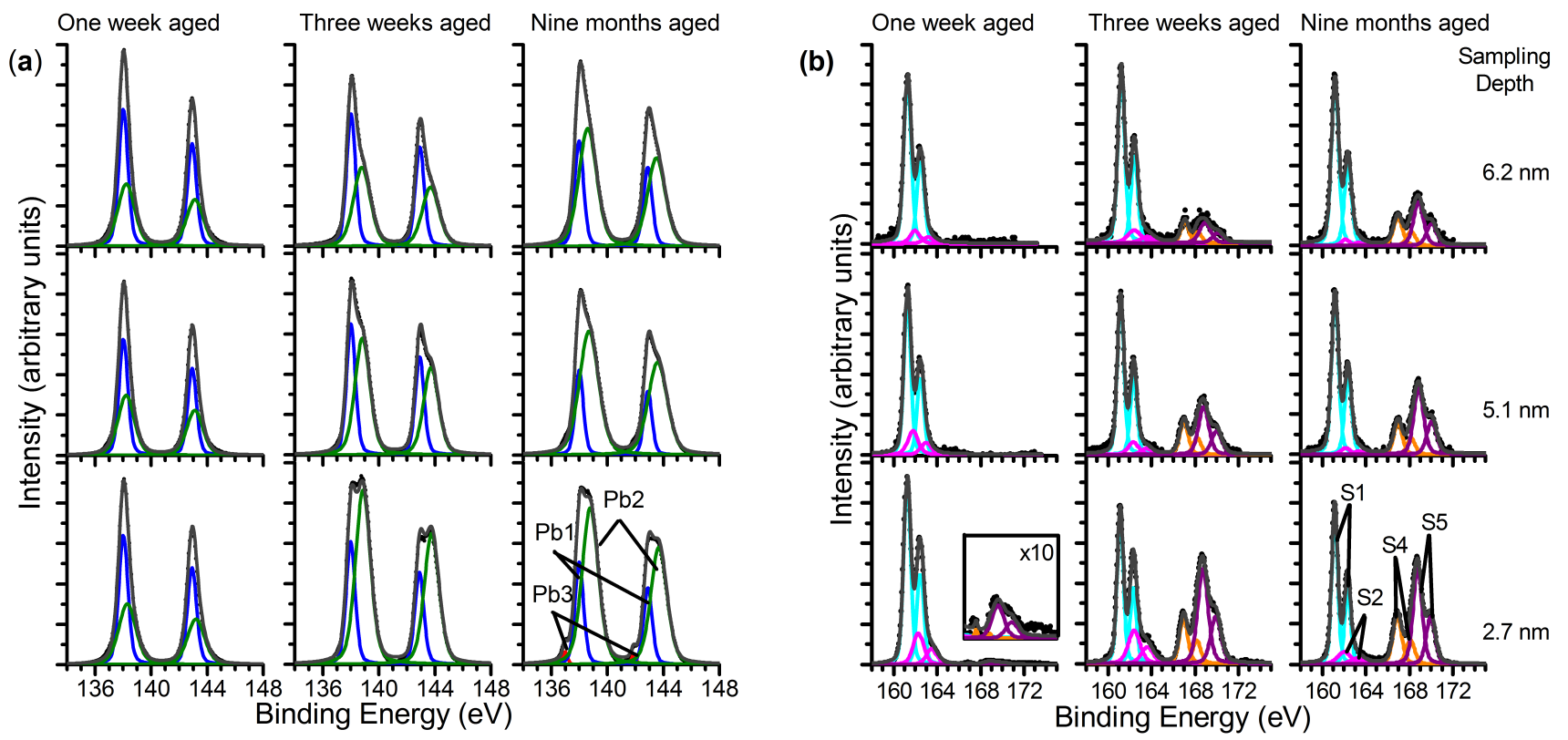

Figure 3. Effect of surface aging time in air on the $\mathrm{Pb} 4 \mathrm{f}(\mathrm{a})$ and $\mathrm{S} 2 \mathrm{p}(\mathrm{b}) \mathrm{XPS}$ spectra of a PbS NC film, synthesised using lead diethyldithiocarbamate precursor, recorded at different sampling depths. Photon energies are $1000 \mathrm{eV}$ (giving $6.2 \mathrm{~nm}$ sampling depth), $800 \mathrm{eV}(5.1 \mathrm{~nm})$, and $400 \mathrm{eV}(2.7 \mathrm{~nm}) .{ }^{53}$

After ageing in air for three weeks, and then for nine months, the intensity of the oxidized lead (Pb2) component increases to become the dominant component of the $\mathrm{Pb} 4 \mathrm{f}$ spectrum. It now shows an increase in intensity at low sampling depth. The corresponding $S 2 p$ spectra show that strong signals due to sulfate (S5) and sulfite (S4) become visible after 3 weeks of ageing. These signals increase in intensity as the sampling depth is decreased, and a similar variation is now observed in the $\mathrm{Pb} 2$ component. We note that $\mathrm{PbSO}_{3}$ and $\mathrm{PbSO}_{4}$, once formed, both contribute to the $\mathrm{Pb} 4 \mathrm{f}$ signal due to oxidized $\mathrm{Pb}$ $(\mathrm{Pb} 2)$. Thus, after longer ageing times (a few weeks) a surface layer of $\mathrm{PbSO}_{3}$ and $\mathrm{PbSO}_{4}$ is produced. The depth distribution of $\mathrm{PbSO}_{3}$ and $\mathrm{PbSO}_{4}$, and the ratio of $\mathrm{PbSO}_{3}$ (S4) to $\mathrm{PbSO}_{4}$ (S5) are not significantly changed by ageing to 9 months. This suggests that the outer sulfate/sulfite layer has a passivating effect on the underlying $\mathrm{PbS}$. This is confirmed by estimation of the layer thickness of the surface sulfite/sulfate layer from the XPS data, shown in Figure 4. The thickness of the oxide layer shows a logarithmic dependence on the sample ageing time, as expected in the growth of a passivating layer (details in the supporting information of reference by Cant et al.). ${ }^{53}$

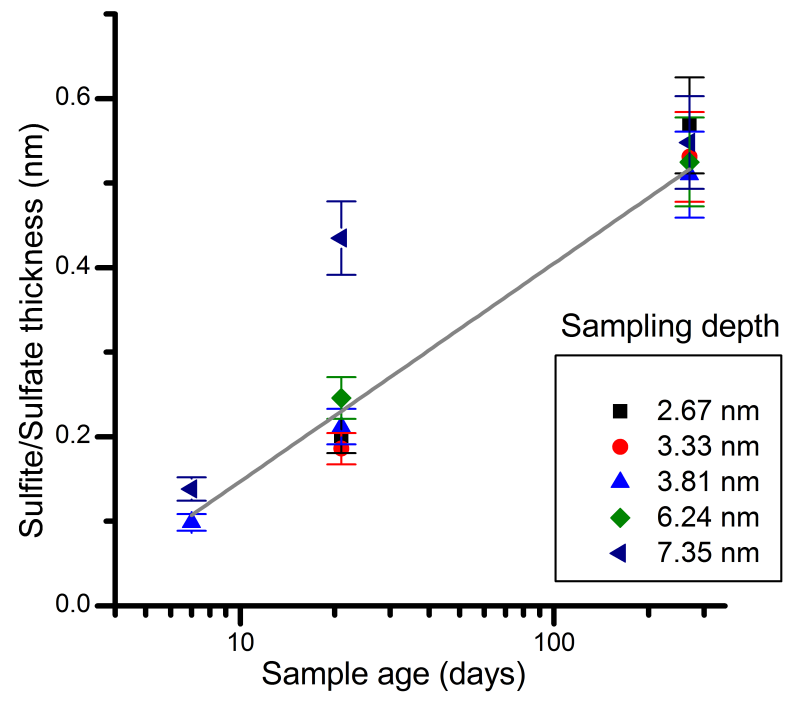

Figure 4. Sulfite/sulfate surface layer thicknesses (estimated from XPS using the approach of Shard ${ }^{39}$ as a function of log(surface aging time) for a PbS NC film. The film was synthesized using synthesised using lead diethyldithiocarbamate precursor. ${ }^{53}$

Table 2. XPS Peak Assignments for PbS NCs ( Figure 3).

$\begin{array}{ll}\text { Literature } & \text { Observed } \\ \text { binding energy } & \text { binding } \\ (\mathrm{eV})^{[\mathrm{a}]} & \text { energies }\end{array}$




\begin{tabular}{|c|c|c|c|}
\hline & & & $(\mathrm{eV})^{[\mathrm{b}]}$ \\
\hline $\mathrm{Pb} 1$ & Lead in $\mathrm{PbS}$ & 138 & $138 \pm 0.1$ \\
\hline $\mathrm{Pb} 2$ & $\mathrm{~Pb}(\mathrm{OH})_{2} / \mathrm{Pb}_{3}(\mathrm{OH})_{2}\left(\mathrm{CO}_{3}\right)_{2}$ & 138.4 & $\begin{array}{l}138.4-138.6 \pm \\
0.1\end{array}$ \\
\hline $\mathrm{Pb} 3$ & Neutral lead & 136.8 & $137.1 \pm 0.1$ \\
\hline S1 & Sulfur in $\mathrm{PbS}$ & 161.0 & $161.2 \pm 0.1$ \\
\hline S2 & Sulfur in $-\mathrm{SO} / \mathrm{S}-\mathrm{C} / \mathrm{SH}$ & $162.3 / 162 / 162.2$ & $162.0 \pm 0.2$ \\
\hline S3 & Sulfur in $-\mathrm{SO}_{2}$ & 163.9 & $163.9 \pm 0.2$ \\
\hline S4 & Sulfur in $\mathrm{SO}_{3}{ }^{2-}$ & 167.1 & $166.9 \pm 0.2$ \\
\hline S5 & Sulfur in $\mathrm{SO}_{4}{ }^{2-}$ & 168.8 & $168.7 \pm 0.2$ \\
\hline $\begin{array}{l}\text { [a] B } \\
\text { of ea }\end{array}$ & erenced to $\mathrm{C} 1 \mathrm{~s}$ at $248.8 \mathrm{e}$ & and refer to the lov & BE component \\
\hline
\end{tabular}

\subsection{Passivation for Air Stability}

There has been a worldwide effort into improving the air stability of CQDs. Lead chalcogenide based CQDs have been at the focus of this research for photovoltaic applications due to their desirable optical properties. However rapid oxidation of their surface can create deep traps or an insulating barrier around the CQD which reduces charge transport efficiency and blue-shifts absorption (Figure 5) as discussed in the previous section. ${ }^{56-59}$
These effects are undesirable and limit the feasibility of using CQDs in devices as performance swiftly reduces with oxidation. ${ }^{60,61}$ Inorganic surface treatments, particularly those involving iodides, have significantly improved the air stability of CQD devices. ${ }^{23,62,63}$ Cation exchange of PbS CQDs with Cd to create sub-monolayer CdS shells has also shown improvements in the passivation of surface traps in PbS CQD-based solar cells. ${ }^{64}$ We have carried out a detailed investigation of the structure of these shells using depth-profiling XPS. In addition, the effect of $\mathrm{Cd}$ in both stabilizing the CQDs against oxidation and modifying the electronic structure was also investigated. ${ }^{40}$

Depth-profiling XPS data showed that the Cd is located on the surface of the $\mathrm{PbS} / \mathrm{CdS} \mathrm{CQDs}$ after cation exchange as the $[\mathrm{Cd}] /[\mathrm{Pb}]$ ratio decreased with sampling depth (Figure $2 \mathrm{~A}$ ). Shell thicknesses were calculated using the depth-profiling XPS data and the methods developed by Shard et al. ${ }^{38,39}$ Only in the case where more than one monolayer of CdS was present on the surface was evidence for alloying into the PbS core found. ${ }^{40}$

As XPS can also give information on the chemical environment of the surface species, it is ideal for probing the extent of oxidation on CQD surfaces after a controlled amount of air exposure. The $S 2 p$ region is an ideal diagnostic tool for identifying surface oxidation on $\mathrm{PbS} C Q D$ s due to the large chemical shifts between species such as sulfite and sulfate. ${ }^{10,40,53,65}$ Using SR-excited XPS not only allows for depth profiling but also for selecting an optimal photon energy to record spectra. For example the $S 2 p$ region has a large problematic background originating from $\mathrm{Pb} 4 \mathrm{f}$ photoexcitation when recorded at high photon energies (such as when using a conventional $\mathrm{Al} \mathrm{K} \alpha$ source). Choosing an excitation photon energy of $390 \mathrm{eV}$ eliminates this problem (whilst also increasing the photoionisation cross section of the $S 2 p$ peak), allowing identification of species and

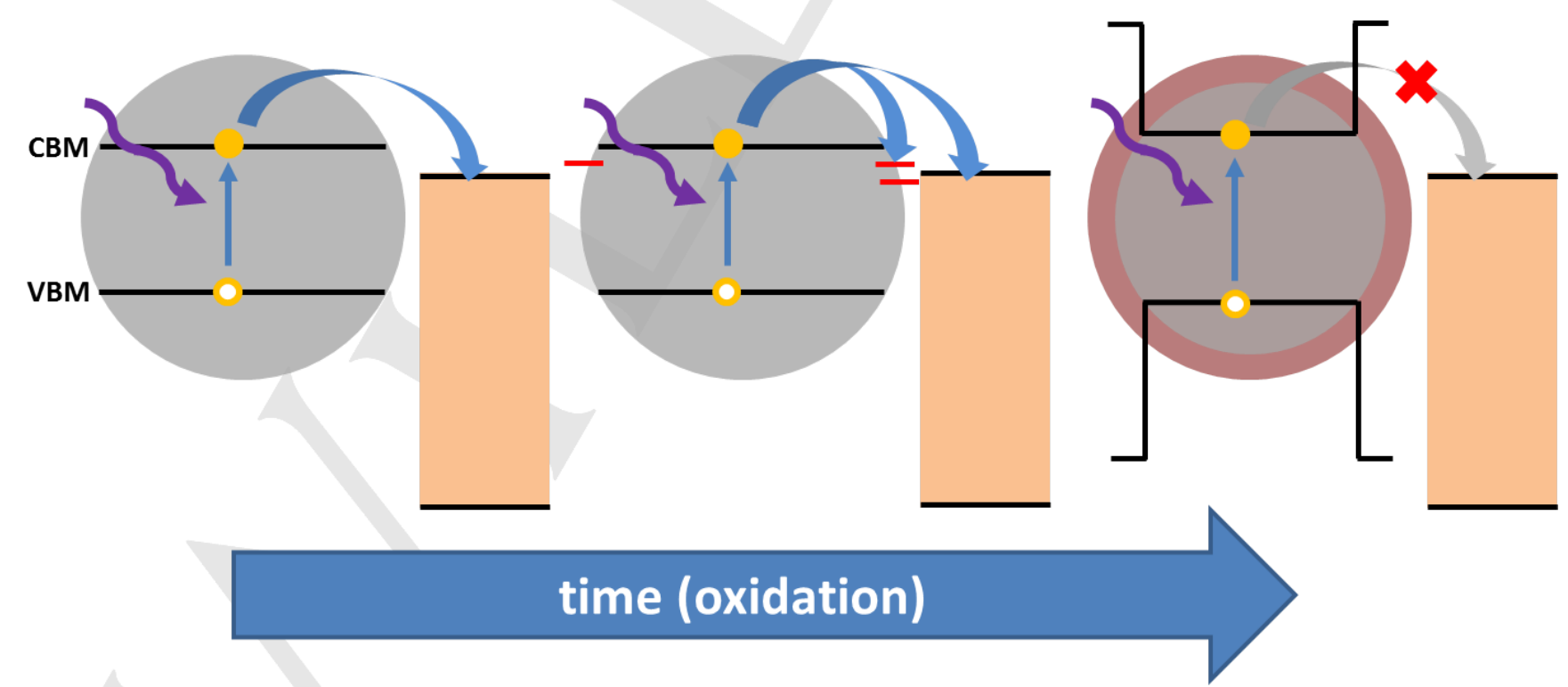

Figure 5. The process of electron transfer from photoexcited PbS CQDs (grey) into a photoanode material (beige) at three different stages in ageing time or oxidation. Left to right: fresh/unoxidized; slightly oxidized surface (shallow traps (red lines) present on surface); heavily oxidized surface (insulating oxide barrier (red) preventing electron transfer) 
adequate fitting of the spectra. Figure $6 \mathrm{~A}$ shows the $S 2 \mathrm{p}$ spectra for PbS CQDs with two different CdS shell thicknesses, and shows that CQDs with a thinner shell have oxide present at the surface while a thicker shell stabilizes the surface against oxidation. The ratio of oxidation products to $\mathrm{PbS}$ for a series of CdS shell thickness is displayed in Figure $6 \mathrm{~B}$, demonstrating that less than a monolayer of CdS on the surface of PbS CQDs is required to protect against short-term oxidation. The thickness at which short-term surface oxidation is eliminated is roughly the same as that which gives the optimum PCE in solar devices. ${ }^{64}$
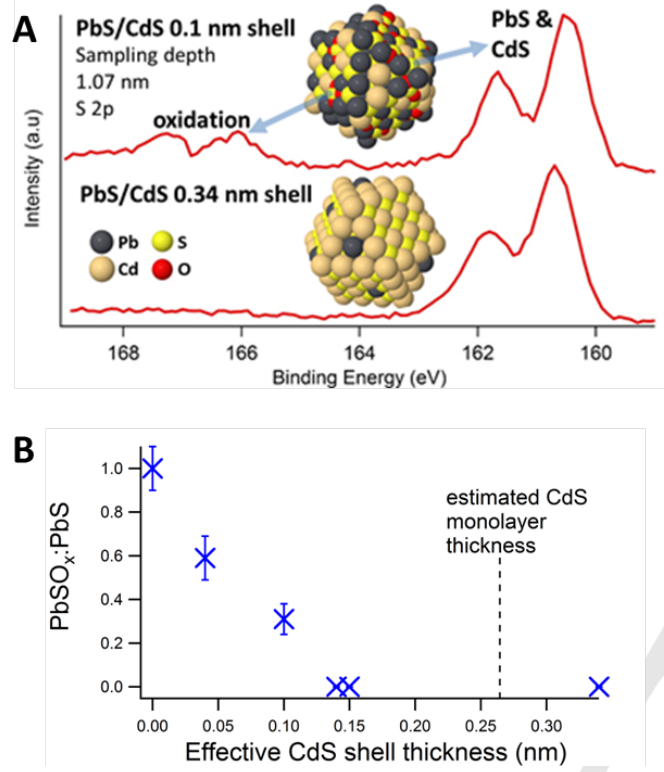

Figure 6. (A) S $2 p$ XPS spectra of PbS CQDs cation exchanged with $C d$ to create an effective shell thickness of $0.1 \mathrm{~nm}$ (top) and $0.34 \mathrm{~nm}$ (bottom) after 30 minutes of air exposure. Oxidation products are present for the $0.1 \mathrm{~nm}$ shell CQD. Schematic diagrams of the CQD surface compositions from XPS (without ligands) are inset. (B) Ratio of amounts of $\left(\mathrm{PbSO}_{3}+\mathrm{PbSO}_{4}\right)$ to $\mathrm{PbS}$ measured in XPS for fresh samples (maximum 30 minutes air exposure) as a function of effective CdS shell thickness. ${ }^{40}$

The effect of cation-exchanged $\mathrm{Cd}$ on the electronic structure of $\mathrm{PbS}$ CQDs was also investigated with valence band photoemission. No change was found in the valence band maximum (VBM) position compared with 'core-only' CQDs for sub-monolayer CdS shells. However shallow trap states form associated with a small amount of lead sulfite ${ }^{57}$ formed at the surface after 5 days' storage in ambient conditions (Figure 7). After 8 months, significant oxidation occurs, and this creates a large insulating barrier of lead sulfate on the surface of the CQDs, prohibiting efficient charge transfer out of CQDs in solar cells applications. For thicker-shelled samples, the VBM position increases slightly, but not as much as would be expected from the bulk band alignments of $\mathrm{PbS}$ and $\mathrm{CdS},{ }^{66}$ and so the CBM of the CdS shell is significantly higher in energy than the PbS core. $^{40}$ This implies a large barrier for charge injection from these CQDs to (for example) a photoanode such as $\mathrm{ZnO}$, and explains the resulting decrease in short circuit current (and therefore PCE) observed by Neo et al. for increasing shell thicknesses of $\mathrm{CdS}^{64}$ The alloying observed with depth-profiling XPS for this thick-shelled sample was also observed as a gradient increase in the VBM between the core and shell (Figure 7).
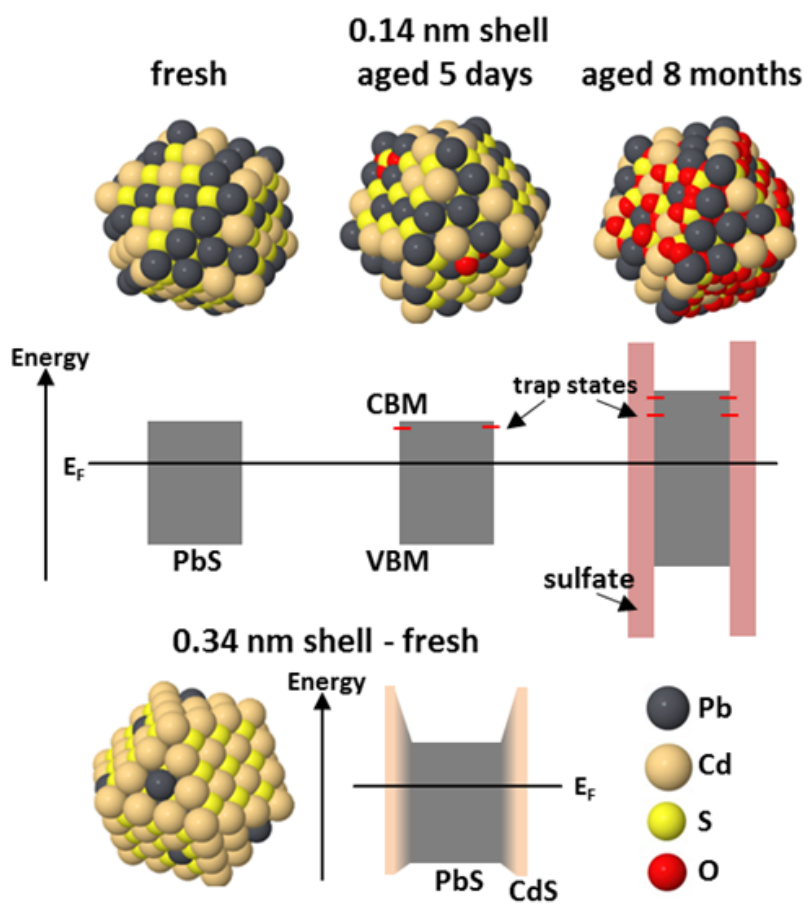

Figure 7. Schematic diagrams of the $\mathrm{PbS} / \mathrm{CdS} \mathrm{CQD}$ structure and band alignment for CQDs with a sub-monolayer $(0.14 \mathrm{~nm}) \mathrm{Cd}$ shell at three stages during ageing, and for CQDs with a thicker $(0.34 \mathrm{~nm})$ shell. In the first case, the electronic structure of the fresh sample is not significantly changed from that of a PbS CQD. Initial oxidation to give small amounts of oxidized sulphur on the surface is accompanied by the appearance of shallow trap states below the conduction band minimum. Once the entire outside of the shell has oxidized, there is a large barrier to charge transport at the CQD surface, the core size is reduced, and deeper trap states are present due to $\mathrm{PbSO}_{4}$. For thicker-shelled CQDs, where alloying was found between the core and shell, the shell produces a barrier to charge transport at the surface. ${ }^{40}$

CdS shells have also been shown (using XPS) to stabilize InP CQDs and improve the QY and efficiency of multiple exciton generation by passivating surface traps. ${ }^{43}$ Another example of depth-profiling XPS illuminating the passivating action of a surface treatment is in chloride-treated CdTe CQDs. ${ }^{41} \mathrm{CdTe}$ CQDs are easily tuned to emit in the visible light range, and so potential applications include light emitting diodes. The addition of a $\mathrm{CdCl}_{2}$ overlayer was shown to improve the photoluminescence quantum yield and air stability of the CQDs, resulting in a record $\mathrm{QY}$ for CdTe of $97 \%{ }^{41}$ 


\subsection{Quantification of Surface Composition}

Depth-profiling XPS allows the species present on the surface after various CQD passivation treatments to be determined, and in optimum cases, this information can be used to quantify the depth-dependent composition in more detail. Using the ratios of elements, the size of the quantum dot, the thickness of the surface layer and the IMFP of the photoelectrons, the signal from the topmost surface layer alone can be isolated. This approach can be used to follow the effect of different stages of multi-step passivation treatments. For example, Figure 8 shows how the surface composition changes after $\mathrm{PbS} / \mathrm{CdS}$ core/shell CQDs are treated with EDT, $\mathrm{Br}$, and $\mathrm{Br}+\mathrm{EDT}$ ligand exchanges. The change in the $\mathrm{Cd}$ percentage on the surface after treatment with $\mathrm{Br}$ alone shows that this treatment etches $\mathrm{Cd}$ from the CQD surface, while the 'EDT-only' treatment does not etch the surface. For the Br+EDT treatment, significant etching does not occur. This is due to a less aggressive, reduced of $\mathrm{Br}$ treatment (one cycle) compared to the $\mathrm{Br}$ only case (three cycles). However, the amount of $\mathrm{Br}$ present on the CQD surface is approximately equal for both the $\mathrm{Br}$ only and $\mathrm{Br}+\mathrm{EDT}$ treatments, showing that a good passivation can be achieved without etching the surface. ${ }^{55}$

The surface compositions were compared to data from solar cell devices incorporating these films, and a study of the air stability of the films (using XPS and optical absorption). ${ }^{55}$ An inverse correlation was found between both good performance and air stability and the amount of unpassivated $\mathrm{Pb}$ and $\mathrm{S}$ sites present on the surface after treatment. This highlights the importance of checking the surface composition of CQD films with XPS. Checking for negative effects such as etching, and aiding the understanding of increased device performance or air stability are among the assets of this quantitative XPS analysis.

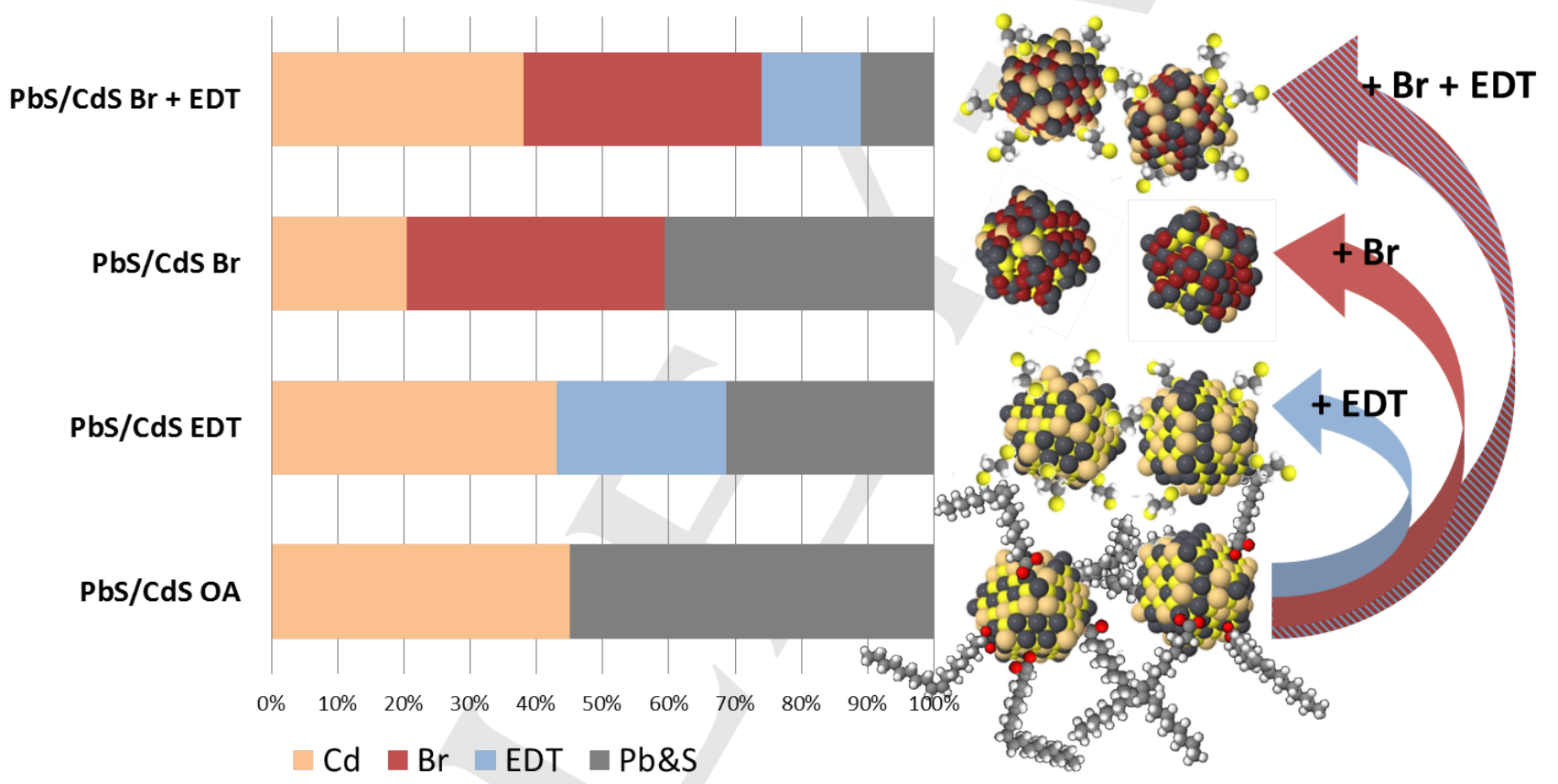

Figure 8. Composition of the surface (top monolayer) of PbS/CdS CQDs after various ligand exchanges (EDT only, $\mathrm{Br}$ only, $\mathrm{Br}$ and $\mathrm{EDT}$ ) as measured by $\mathrm{X}$-ray Photoelectron Spectroscopy. The beige bars represent the percentage of the surface $\mathrm{Pb}$ cation exchanged for $\mathrm{Cd}$, red represents $\mathrm{Br}$ bound to $\mathrm{Pb}$, blue represents a thiol from EDT ligands bound to the surface, and grey represents the percentage of the available surface sites that remains as PbS (non-stoichiometric). Schematic diagrams of the CQDs at each stage are shown on the right (note the number of organic ligands shown is under-representative). ${ }^{55}$

\section{Summary and Outlook}

SR-excited depth-profiling XPS is a powerful technique, combining layer-by-layer probing of nanoscale objects with chemical and electronic characterization. We have demonstrated the application of this technique to problems of oxidation and passivation of NCs of interest for next-generation solar cells.
Overall, our study on oxidation mechanisms in PbS NCs shows that Initial degradation occurs to form lead hydroxide and small quantities of surface-adsorbed -SH species. A lead-deficient $\mathrm{Pb}_{1-\mathrm{x}} \mathrm{S}$ phase is produced as the ageing proceeds. Oxidation of the sulfur occurs later to form a sulfite and sulfate passivating layer that is highly localized at the surface layers of the nanocrystals. Our results demonstrate that the initial reaction of the $\mathrm{PbS}$ nanocrystals (forming lead hydroxide) is incongruent.

We also demonstrate the passivating action of $\mathrm{Cd}$ on the surface of PbS CQDs. The CdS shell thickness is found to correlate with 
both the electronic structure at the VBM and extent of oxidation of the CQD surface. A sub-monolayer shell is effective in protecting against oxidation and reducing formation of an insulating barrier at the surface. This work has been continued to study PbS CQDs after further surface treatments have been performed. By measuring XPS of the surface at each stage, the change in surface composition and therefore the effect that each treatment has on the CQD surfaces can be determined. This is important for understanding why certain treatments are more successful in producing CQDs with a higher air stability and better performing in solar cells. In our work we show that the extent of oxidation is directly correlated with the number of unpassivated sites at the CQD surface.

As CQD technologies rapidly improve towards commercial standards, surface characterization will continue to play a large role in our understanding and in development of new devices.. In particular, strongly coupled CQD solids, where the CQDs form organized structures within the solid, have properties highly dependent on the surface chemistry of the CQDs. ${ }^{45}$ Studies of detailed surface characterization and electronic structure combined with measurements of carrier dynamics will be critical to a full understanding of these materials.

\section{Acknowledgements}

We thank the European Community's Seventh Framework Programme (FP7/2007-2015) which allowed access to Synchrotron SOLEIL, Elettra, and MAX-lab under grant agreements no. 226716, and 288879. .We also acknowledge David J. H. Cant, Darren C. J. Neo, Simon M. Fairclough, Igor Pis, Karsten Handrup, and Mathieu G. Silly for their involvement in this work. Pip. C. J. Clark thanks the University of Manchester for the award of a President's Doctoral Scholarship. Data associated with this account are available at the following data repositories DOI:10.15127/1.305124 DOI:10.17632/6nv8y2x3jj.1.

Keywords: quantum dot $\cdot$ depth-profiling $\cdot X$-ray photoelectron spectroscopy $\cdot$ nanocrystal $\cdot$ surface characterization

1 H. Goodwin, T. C. Jellicoe, N. J. L. K. Davis, M. L. Böhm, Nanophotonics 2018, 7, 111.

2 D. Bera, L. Qian, T. K. Tseng, P. H. Holloway, Materials (Basel). 2010, 3, 2260

3 E. M. Sanehira, A. R. Marshall, J. A. Christians, S. P. Harvey, P. N. Ciesielski, L. M. Wheeler, P. Schulz, L. Y. Lin, M. C. Beard, J. M. Luther, Sci. Adv. 2017, Accepted. Martins, F. Vanhaecke, A. Vantomme, C. Delerue, G. Allan, Z. Hens, ACS Nano 2009, 3, 3023. W. Shockley, H. J. Queisser, J. Appl. Phys. 1961, 32, 510. A. Bakulin, S. Neutzner, H. J. Bakker, L. Ottaviani, D. Barakel, Z. Chen, ACS Nano 2013, 7, 8771
Lee, P. Giraud, S. Lee, J. B. Park, S. M. Morris, H. J. Snaith, J. I. Sohn, S. Cha, J. M. Kim, J. Mater. Chem. A 2016, 4, 18769.

\section{Chem. C 2014, 2, 4442.}

J. Zhang, J. Gao, C. P. Church, E. M. Miller, J. M. Luther, V. I. Klimov, M. C. Beard, Nano Lett. 2014, 14, 6010.

S. J. O. Hardman, D. M. Graham, S. K. Stubbs, B. F. Spencer, E. A Seddon, H.-T. Fung, S. Gardonio, F. Sirotti, M. G. Silly, J. Akhtar, P. O'Brien, D. J. Binks, W. R. Flavell, Phys. Chem. Chem. Phys. 2011, 13, 20275

M. C. Beard, R. J. Ellingson, Laser Photonics Rev. 2008, 2, 377. X. Lan, O. Voznyy, F. P. García De Arquer, M. Liu, J. Xu, A. H. Proppe, G. Walters, F. Fan, H. Tan, M. Liu, Z. Yang, S. Hoogland, E. H. Sargent, Nano Lett. 2016, 16, 4630.

B. F. Spencer, M. J. Cliffe, D. M. Graham, S. J. O. Hardman, E. a Seddon, K. L. Syres, A. G. Thomas, F. Sirotti, M. G. Silly, J. Akhtar, P. O'Brien, S. M. Fairclough, J. M. Smith, S. Chattopadhyay, W. R. Flavell, Faraday Discuss. 2014, 171, 275.

L. Y. Chang, R. R. Lunt, P. R. Brown, V. Bulovic, M. G. Bawendi, Nano Lett. 2013, 13, 994.

W. Lee, H. Kim, D.-R. Jung, J. Kim, C. Nahm, J. Lee, S. Kang, B. Lee, B. Park, Nanoscale Res. Lett. 2012, 7, 672.

J. Zhang, J. Tolentino, E. R. Smith, J. Zhang, M. C. Beard, A. J. Nozik, M. Law, J. C. Johnson, J. Phys. Chem. C 2014, 118, 16228. B. F. Spencer, M. A. Leontiadou, P. C. J. Clark, A. Williamson, M. G. Silly, F. Sirotti, S. M. Fairclough, D. C. J. Neo, A. A. R. Watt, W. R. Flavell, Appl. Phys. Lett. 2016, 108, 091603.

J. Tang, K. W. Kemp, S. Hoogland, K. S. Jeong, H. Liu, L. Levina, M. Furukawa, X. Wang, R. Debnath, D. Cha, K. W. Chou, A. Fischer, A. Amassian, J. B. Asbury, E. H. Sargent, Nat. Mater. 2011, 10, 765. J. Gao, C. L. Perkins, J. M. Luther, M. C. Hanna, H.-Y. Chen, O. E. Semonin, A. J. Nozik, R. J. Ellingson, M. C. Beard, Nano Lett. 2011, 11, 3263.

A. H. Ip, S. M. Thon, S. Hoogland, O. Voznyy, D. Zhitomirsky, R. Debnath, L. Levina, L. R. Rollny, G. H. Carey, A. Fischer, K. W. Kemp, I. J. Kramer, Z. Ning, A. J. Labelle, K. W. Chou, A. Amassian, E. H. Sargent, Nat. Nanotechnol. 2012, 7, 577 .

1 Z. Ning, O. Voznyy, J. Pan, S. Hoogland, V. Adinolfi, J. Xu, M. Li, A. R. Kirmani, J.-P. Sun, J. Minor, K. W. Kemp, H. Dong, L. Rollny, A. Labelle, G. Carey, B. Sutherland, I. Hill, A. Amassian, H. Liu, J. Tang, O. M. Bakr, E. H. Sargent, Nat. Mater. 2014, 13, 822. Z. Zhang, J. Yang, X. Wen, L. Yuan, S. Shrestha, J. A. Stride, G. J. Conibeer, R. J. Patterson, S. Huang, J. Phys. Chem. C 2015, 119, 24149.

L. Yuan, R. Patterson, W. Cao, Z. Zhang, Z. Zhang, J. A. Stride, P. Reece, G. Conibeer, S. Huang, RSC Adv. 2015, 5, 68579.

R. Azmi, S. Sinaga, H. Aqoma, G. Seo, T. Kyu, M. Park, Nano Energy 2017, 39, 86.

R. Wang, X. Wu, K. Xu, W. Zhou, Y. Shang, H. Tang, H. Chen, Z. Ning, Adv. Mater. 2018, 30, 1704882.

D.-K. Ko, A. Maurano, S. K. Suh, D. Kim, G. W. Hwang, J. C. Grossman, V. Bulović, M. G. Bawendi, ACS Nano 2016, acsnano.5b07186.

R. Wang, Y. Shang, P. Kanjanaboos, W. Zhou, Z. Ning, E. H. 
Sargent, Energy Environ. Sci. 2016, 9, 1130

M. Mahboub, P. Xia, J. Van Baren, X. Li, C. H. Lui, M. L. Tang, ACS Energy Lett. 2018, 3, 767

Z. Yang, A. Janmohamed, X. Lan, F. P. García De Arquer, O.

Voznyy, E. Yassitepe, G. H. Kim, Z. Ning, X. Gong, R. Comin, E. H. Sargent, Nano Lett. 2015, 15, 7539.

M. Sytnyk, S. Yakunin, W. Schöfberger, R. T. Lechner, M. Burian, L. Ludescher, N. A. Killilea, A. Yousefiamin, D. Kriegner, J. Stangl, H. Groiss, W. Heiss, ACS Nano 2017, 11, 1246.

D. C. J. Neo, C. Cheng, S. D. Stranks, S. M. Fairclough, J. S. Kim, A. I. Kirkland, J. M. Smith, H. J. Snaith, H. E. Assender, A. a R. Watt, Chem. Mater. 2014, 26, 4004.

P. R. Brown, D. Kim, R. R. Lunt, N. Zhao, M. G. Bawendi, J. C. Grossman, V. Bulovi, ACS Nano 2014, 8, 5863.

R. W. Crisp, D. M. Kroupa, A. R. Marshall, E. M. Miller, J. Zhang, M. C. Beard, J. M. Luther, Sci. Rep. 2015, 5, 9945.

C.-H. M. Chuang, P. R. Brown, V. Bulović, M. G. Bawendi, 2014, 13, 796.

A. R. Kirmani, A. D. Sheikh, M. R. Niazi, M. A. Haque, M. Liu, F. P G. de Arquer, J. Xu, B. Sun, O. Voznyy, N. Gasparini, D. Baran, T. Wu, E. H. Sargent, A. Amassian, Adv. Mater. 2018, 1801661. S. R. Tulsani, A. K. Rath, J. Colloid Interface Sci. 2018, 522, 120. M. P. Seah, W. A. Dench, Surf. Interface Anal. 1979, 1, 2. A. G. Shard, J. Wang, S. J. Spencer, Surf. Interface Anal. 2009, 41, 541.

A. G. Shard, J. Phys. Chem. C 2012, 116, 16806.

P. C. J. Clark, H. Radtke, A. Pengpad, A. I. Williamson, B. F. Spencer, J. O. Hardman, M. A. Leontiadou, D. C. J. Neo, S. M. Fairclough, A. A. R. Watt, I. Pis, S. Nappini, F. Bondino, E. Magnano, K. Schulte, M. Silly, F. Sirotti, W. R. Flavell, Nanoscale 2017, 9, 6056.

R. C. Page, D. Espinobarro-Velazquez, M. A. Leontiadou, C. Smith, E. A. Lewis, S. J. Haigh, C. Li, H. Radtke, A. Pengpad, F. Bondino E. Magnano, I. Pis, W. R. Flavell, P. O'Brien, D. J. Binks, Small 2014, 11, 1548.

S. M. Fairclough, E. J. Tyrrell, D. M. Graham, P. J. B. Lunt, S. J. O. Hardman, A. Pietzsch, F. Hennies, J. Moghal, W. R. Flavell, A. a. R. Watt, J. M. Smith, J. Phys. Chem. C 2012, 116, 26898. C. T. Smith, M. A. Leontiadou, P. C. J. Clark, C. Lydon, N. Savjani, B. F. Spencer, W. R. Flavell, P. O'Brien, D. J. Binks, J. Phys. Chem. C 2017, 121, 2099.

R. Saran, R. J. Curry, Nat. Photonics 2016, 10, 81.

C. R. Kagan, C. B. Murray, Nat. Nanotechnol. 2015, 10, 1013. M. Sykora, A. Y. Koposov, J. A. Mcguire, R. K. Schulze, O. Tretiak, J. M. Pietryga, V. I. Klimov, 2010, 4, 2021

M. A. Hampton, C. Plackowski, A. V. Nguyen, Langmuir 2011, 27, 4190.

P. K. Abraitis, R. A. D. Pattrick, G. H. Kelsall, D. J. Vaughan,

Mineral. Mag. 2004, 68, 343.

51

52
T. Shimizu, M. Masuda, H. Minamikawa, Chem. Rev. 2005, 105 , 1401.

K. Laajalehto, I. Kartio, E. Suoninen, Int. J. Miner. Process. 1997, 51, 163.

A. N. Buckley, R. Woods, Appl. Surf. Sci. 1984, 17, 401. I. Kartio, G. Wittstock, K. Laajalehto, D. Hirsch, J. Simola, T. Laiho, R. Szargan, E. Suoninen, Int. J. Miner. Process. 1997, 51, 293. D. J. H. Cant, K. L. Syres, P. J. B. Lunt, H. Radtke, J. Treacy, P. J. Thomas, E. A. Lewis, S. J. Haigh, P. O. Brien, K. Schulte, F. Bondino, E. Magnano, W. R. Flavell, Langmuir 2015, 31, 1445. J. Akhtar, M. Azad Malik, P. O'Brien, K. G. U. Wijayantha, R. Dharmadasa, S. J. O. Hardman, D. M. Graham, B. F. Spencer, S. K. Stubbs, W. R. Flavell, D. J. Binks, F. Sirotti, M. El Kazzi, M. Silly, J. Mater. Chem. 2010, 20, 2336.

P. C. J. Clark, D. C. J. Neo, R. Ahumada-Lazo, A. I. Williamson, I. Pis, S. Nappini, A. A. R. Watt, W. R. Flavell, Langmuir 2018, 34, 8887.

G. Konstantatos, E. H. Sargent, Appl. Phys. Lett. 2007, 91, 173505. J. Tang, L. Brzozowski, D. A. R. Barkhouse, X. Wang, R. Debnath, R. Wolowiec, E. Palmiano, L. Levina, A. G. Pattantyus-Abraham, D. Jamakosmanovic, E. H. Sargent, ACS Nano 2010, 4, 869.

S. Kahmann, M. Sytnyk, N. Schrenker, G. J. Matt, E. Spiecker, W. Heiss, C. J. Brabec, M. A. Loi, Adv. Electron. Mater. 2018, 4, 1700348.

H. Beygi, S. A. Sajjadi, A. Babakhani, J. F. Young, F. C. J. M. van Veggel, Appl. Surf. Sci. 2018, 457, 1.

J. Tang, X. Wang, L. Brzozowski, D. A. R. Barkhouse, R. Debnath, L. Levina, E. H. Sargent, Adv. Mater. 2010, 22, 1398.

Y. Cao, A. Stavrinadis, T. Lasanta, D. So, G. Konstantatos, Nat. Energy 2016, 1, 16035.

C.-H. M. Chuang, P. R. Brown, V. Bulović, M. G. Bawendi, Nat. Mater. 2014, 13, 796

X. Lan, O. Voznyy, A. Kiani, F. P. Garcia De Arquer, A. S. Abbas, G. H. Kim, M. Liu, Z. Yang, G. Walters, J. Xu, M. Yuan, Z. Ning, F. Fan, P. Kanjanaboos, I. Kramer, D. Zhitomirsky, P. Lee, A. Perelgut, S. Hoogland, E. H. Sargent, Adv. Mater. 2016, 28, 299. D. C. J. Neo, C. Cheng, S. D. Stranks, S. M. Fairclough, J. S. Kim A. I. Kirkland, J. M. Smith, H. J. Snaith, H. E. Assender, A. A. R. Watt, Chem. Mater. 2014, 26, 4004

A. Lobo, T. Möller, M. Nagel, H. Borchert, S. G. Hickey, H. Weller, J. Phys. Chem. B 2005, 109, 17422.

K. P. Bhandari, H. Choi, S. Jeong, H. Mahabaduge, R. J. Ellingson, Appl. Phys. Lett. 2014, 105, 131604. 
Entry for the Table of Contents (Please choose one layout)

\section{Layout 1:}

\section{PERSONAL ACCOUNT}

In this account we discuss photoemission techniques for characterizing the surfaces of colloidal quantum dots and nanoparticles, and how synchrotron radiation-excited depth-profiling XPS can expand our understanding of processes and behaviours of nanoscale materials. We illustrate application of this technique to understanding oxidation mechanisms and passivation treatments.
Pip C. J. Clark and Wendy R. Flavell

$$
\text { Page No. - Page No. }
$$

Surface and Interface Chemistry in Colloidal Quantum Dots for Solar Applications 


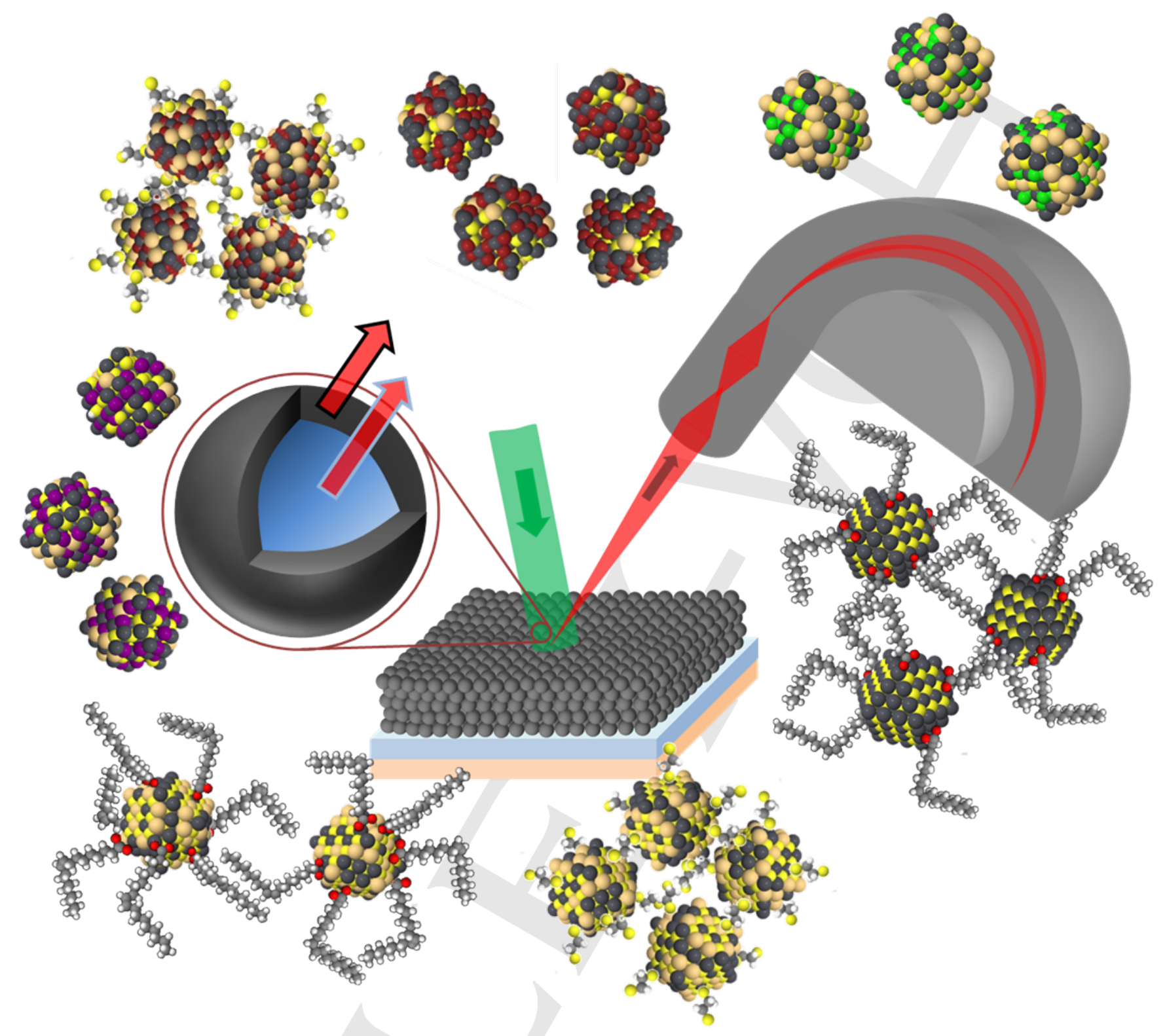

Layout 2:

PERSONAL ACCOUNT

((Insert TOC Graphic here)) 
Page No. - Page No.

Title 